\title{
Roland Barthes, entre o clássico e a vanguarda
}

\author{
Francisco Bosco
}

Os textos de vanguarda costumam oferecer resistência. Interferem no ritmo da leitura, exigindo seu retardamento. Fazem-no por erosão semântica - chegam à destruição semântica, em casos mais radicais -, recusa à caução do real, contorcionismo sintático, entre outros procedimentos. Embora, estruturalmente, busquem a velocidade - por subtração: cortes, elipses, concisão -, da perspectiva do leitor uma tal operação textual resulta precisamente em seu contrário: a lentidão. Quanto mais o texto economiza, mais o leitor dispende, quanto mais vazios no texto, mais o leitor deve preenchê-los. Os textos de vanguarda afetam, portanto, a temporalidade da leitura, obrigando-a a um ritmo lento, minucioso, concentrado.

Como se sabe, uma das diferenças em que se baseia a tipologia desenvolvida por Barthes*, distinguindo "textos de prazer" e "textos de gozo", situa-se justamente na temporalidade da leitura: os textos de prazer - também ditos "clássicos" ou "legíveis" - não oferecem resistência, proporcionam uma leitura fluente, desimpedida, convidam mesmo a pular passagens, sem perda de entendimento; já os textos de gozo - igualmente chamados de "modernos" ou "escrevíveis" exigem uma leitura "aplicada" cia dessa exigência, punir o leitor com o tédio, a improdutividade e, finalmente, a capitulação: abandona-se o texto. Não respeitar as temporalidades respectivas pode, assim, causar aborrecimento: o tédio ameaça acometer tanto a leitura aplicada, minuciosamente detida, do texto de prazer quanto a leitura rápida, dispersa, do texto de gozo. Fique

\footnotetext{
1 “Ora, paradoxalmente (tanto a opinião crê que basta ir rápido para não se entediar), essa segunda leitura, aplicada (em sentido próprio), é aquela que convém ao texto moderno, ao tex to limite. Leia lentamente, leia tudo de um romance de Zola, o livro cairá de suas mãos; leia rápido [...] um texto moderno, esse tex to torna-se opaco, excluído a seu prazer" (Barthes, Roland. Le plaisir du texte. Ob. cit.: 90).
}

-(Barthes, Roland. Le plaisir du texte. Paris: Seuil, 2000.) 
por enquanto suspensa a questão de saber se o tédio não é parte irredutível da leitura do texto de gozo, mesmo ajustando-se sua temporalidade - ou até por isso: afinal, não é o tédio uma espécie radical de lentidão, uma paralisia? ${ }^{2}$

Estabelecida essa diferença de ritmos de leitura - e suas respectivas práticas textuais -, pode-se perguntar como Barthes se situa diante dela. Pergunta a que se pode responder com uma bifurcação: enquanto leitor, Barthes se assume e se afirma um sujeito contraditório, que não recusa nenhuma das temporalidades, que vive entre o regime "confortável" da leitura do texto de prazer $^{3} \mathrm{e}$ a exigência de produtividade da leitura do texto de gozo; como escritor, Barthes diz repetidas vezes que escreve "clássico", que é "legível”", aproximando-se, portanto, de uma temporalidade mais fluida, mais desprovida dos obstáculos que costumam se apresentar ao leitor de textos de vanguarda, retardando-lhe a leitura.

A temporalidade da leitura promovida pelo texto barthesiano conjuga, a meu ver, aspectos das duas temporalidades até aqui indicadas. Do texto "clássico" ela herda a fluência, a agilidade, o baixo grau de resistência; do texto moderno, a alta produtividade - o que, em termos de ritmo, pode ser assim descrito: uma sucessão de tempos velozes; o tempo da

\footnotetext{
${ }^{2}$ Se o que confere rapidez à leitura é, entre outras coisas (como uma sintaxe direta, um alto grau de determinação contextual etc.), talvez principalmente a coerência semântica, o tex to de vanguarda, ao erodir o sentido, isto é, criar associações semânticas inesperadas (cujo modelo, no limite, seria a definição reverdiana da imagem: aproximação de duas realidades distantes, de onde sai a "faísca", a iluminação da imagem surrealista), retarda o fluxo do sentido, rasura-o. Daí uma outra tipologia possível entre a leveza e o peso do texto: aquela seria da ordem da movimentação ágil da leitura, deslizando no fluxo semântico; este, o peso do texto, designaria a leitura retardada pelo sentido rasurado, pois o peso é o que dificulta o movimento, retira a mobilidade - onde se reencontra a figura do tédio, sua paralisia (com a ressalva de que a paralisia, na experiência dos textos de vanguarda, é apenas um dos aspectos da composição da leitura: uma vez enfrentada, pode dar lugar a uma intensa movimentação de pensamento, de produção de sentidos).

s "Texto de prazer: aquele que contenta, enche, dá euforia; aquele que vem da cultura, não rompe com ela, é ligado a uma prática confortável da leitura" (Barthes, Roland. Le plaisir du texte. Ob. cit.: 92).

${ }^{4}$ Como, por exemplo, nesta passagem: "meu texto é, com efeito, legível: estou do lado da estrutura, da frase, do texto fraseado: produzo para reproduzir, como se eu tivesse um pensamento e o representasse com a ajuda de materiais e regras: escrevo clássico" (Barthes, Roland. Roland Barthes por Roland Barthes. São Paulo: Estação Liberdade, 2003: 107).
} 
leitura de olhos baixos, ao rés do texto, desencadeando um outro tempo, também ele ágil, da leitura de olhos afastados do texto, isto é, o desencadeamento de significantes a partir do texto prolongando-se à relativa distância desse $\mathrm{e}^{5}$. Por ser concentrado - operar com a elipse e seus significantes condensados - o texto barthesiano dilata a leitura: pode-se ficar muito tempo na mesma página, ou no mesmo fragmento; mas esse "muito tempo" é, enquanto ritmo, ágil, fluente, desimpedido: tempo de associações, tempo de movimento. Uma leitura, a um só tempo, dilatada e veloz. Mas atenção: um texto não é "isotropo". Pode conter irregularidades, zonas de maior resistência, dificuldades, opacidades ${ }^{6}$. É questionável se uma tal topologia pode, no limite, ser analisada "objetivamente" (na medida em que os pontos de resistência, envolvendo o repertório particular de cada leitor, podem não ser os mesmos), mas o exame de certas categorias como legibilidade, ilegibilidade, transparência, entre outras, possibilita uma maior compreensão das práticas textuais e suas implicações relativamente ao ato da leitura.

Como se pensar, então, a legibilidade? Ou ainda, é a legibilidade uma categoria pertinente? Em um dos textos reunidos em seu Sollers écrivain, Barthes encena um diálogo em que alguém afirma ser o escritor da Tel Quel ilegível, ao que o outro "personagem" responde negativamente, dizendo tratar-se simplesmente de uma questão de adequação de ritmo de leitura. Em outro lugar, Barthes ressalta que não há nenhum critério objetivo para se definir a legibilidade ou a ilegibilidade, e afirma ainda que a idéia de legibilidade está ligada a "um modelo clássico vindo da escola: ser legível é

${ }^{5}$ Essa leitura de "olhos afastados", "à relativa distância do texto", é o que Barthes chama de lire en lévant la tête (ver, por exemplo, Barthes, Roland. Le plaisir du texte. Ob. cit: 99), e que proponho traduzir como "ler de cabeça erguida", para ressaltar a liberdade afirmativa, segura, desse momento da leitura em que o leitor, a partir do texto lido, levanta a cabeça para fazer associações que, apesar de desencadeadas pelo texto lido, podem afastar-se dele, rumo a um outro texto, futuro.

${ }^{6}$ Da legibilidade de Barthes pode-se dizer, embora provavelmente por outros motivos, o mesmo que ele diz sobre Michelet: "É certo que Michelet é um escritor clássico (legível) [...] A legibilidade de Michelet, no entanto, não é segura; é muitas vezes periclitante, comprometida por excessos, desfocagens, rupturas, fugas". Barthes, Roland. O rumor da língua. Lisboa: Edições 70, 1987: 181. 
"(Barthes, Roland. Le plaisir du texte. Ob. cit.: 120.)

(Barthes, Roland. S/Z. Pa ris: Seuil, 1976: 10.) ser lido na escola”' Por aí se percebe o quanto o pensamento sobre a legibilidade está associado ao seu contrário, ou seja, a ilegibilidade. Mas devemos perguntar: o que é a ilegibilidade? Ou, precisando novamente a questão, a ilegibilidade é uma categoria pertinente? Dito de modo simples, existe o campo da ilegibilidade em literatura (incluindo aí a teoria literária)? Como mencionado, os textos de vanguarda, resistentes, portanto ilegíveis à leitura rápida, requerem um outro ritmo, uma leitura aplicada, a partir da qual deixam de ser ilegíveis. Por mais radical que se queira a destruição do sentido - os procedimentos corrosivos -, no limite o sentido invariavelmente a tudo recupera: a História recupera (reconstruindo os contextos de emergência das práticas textuais), a análise crítica recupera (revelando o mecanismo - isto é, dando sentido - pelo qual um texto procura esquivar-se ao sentido), mesmo a interpretação recupera (pois os textos mais "ilegíveis" são, paradoxalmente, aqueles que, por indeterminação radical, oferecem maior liberdade associativa ao leitor, a mais livre produção de sentidos, já que se o texto não os autoriza, também não os proíbe). Daí Barthes dizer que “a vanguarda é a linguagem recessiva [rétif] que será recuperada"*.

A ilegibilidade, portanto, é de existência duvidosa. Acredito que Barthes tenha conseguido reencaminhar a questão ao deslocar o eixo da diferença: em vez de legível/ilegível, surge a conhecida tipologia legível/“escrevível” (lisible) scriptible), tal como é desenvolvida em $S / Z$. Pois agora o "contrário” do legível não é o ilegível, mas um outro legível: como se sabe, os textos lisibles são aqueles que detêm um "plural limitado”, que, de certa forma (e isso sob muitas aspas), existem antes da leitura, ao passo que os textos scriptibles (a rigor, o "escrevível” não se situa no texto: "somos nós, enquanto escrevemos")", abertos a um plural ilimitado, só se tornam possíveis pelo engajamento radical da produtividade do leitor. O leitor os escreve, decide o tempo todo pelo sentido, já que o texto lhe oferece balizas nada estáveis. Os textos legíveis procedem por ambivalência ou polissemia; os textos

7 “Mas, de modo geral, eu ressaltaria desde já que não há nenhum critério objetivo da legibilidade ou da ilegibilidade. Em seguida, diria que ser legível é um modelo clássico vindo da escola: ser legível é ser lido na escola” (Barthes, Roland. O grão da voz. Rio de Janeiro: Francisco Alves, 1995: 360.) 
"escrevíveis", por indecidibilidade. A polissemia é uma multiplicidade de sentidos; graficamente falando, são linhas superpostas de sentido. Já o indecidível não oferece, imediatamente, sentido algum; só o trabalho de leitura pode os fazer surgir. Mas é preciso dirimir algumas imprecisões. Barthes acena com um caminho fecundo nessa formulação de seu Sur Racine: "a literatura é, a um só tempo, sentido posto e sentido retirado"*. Dessa diferença pode-se então derivar a outra, tornando-a mais precisa: o texto legível, polissêmico, intensifica a parte do sentido posto, enquanto o tex to "escrevível", indecidível, radicaliza a parte do sentido retirado.

Ora, para Barthes, é justamente a economia particular da escrita de Racine relativamente a esses dois pólos (sentido posto, sentido retirado), que faz dele, "por uma arte inigualável da disponibilidade", "sem dúvida o maior escritor francês"*. Essa economia Barthes associa à idéia de uma "transparência clássica". E confere à transparência um valor "ambíguo": "ela é ao mesmo tempo aquilo sobre o que não há nada a dizer, e aquilo sobre o que há o máximo a dizer”* Por quê? Pois, por operar generosamente com o sentido posto, reduz a parte produtiva do leitor, seu "dizer"; ao mesmo tempo, por não negligenciar o sentido decepcionado, recoloca o leitor no seu lugar de produtividade, de "dizer". Assim, por um "paradoxo notável”, a linguagem, clássica, de Racine é aquela que "fez convergir para si todas as linguagens novas do século"*; pois o que torna um texto capaz de atravessar séculos e continuar "dizendo" algo aos leitores é esse seu lugar tensivo, zona de vazio e preenchimento (sentido posto/ retirado, abertura, interrogação, nunca resposta, fechamento), e a relação também tensiva entre texto e história (cada época preenchendo o texto a partir de seu próprio repertório). A "inigualável disponibilidade" de Racine estaria portanto no equlíbrio tenso entre sentido posto e sentido retira-

${ }^{8}$ Ao analisar Racine, Barthes fala em transparência, que, nesse contexto, trata-se de uma categoria positivada. Em outros momentos, entretanto, Barthes fala em clareza, e aí essa categoria aparece ora como um mito (a clareza como pseudonaturalidade da língua francesa e sua suposta vocação racional; a clareza como suposto grau zero da significância - experiência sensual do significante -, professada pelos sorbonnards), ora como uma idéia associada à representação: "não há 'clareza' sem uma concepção clássica do signo, o significante de um lado, o referente de outro, o primeiro a serviço do segundo" (cf. a esse respeito, Barthes, Roland. Criticism and truth. Minneapolis: University of Minnesota Press, 1987: 46-52, 181, respectivamente).

" [sens posé et sens déçu]. Barthes. Sur Racine.

Paris: Seuil, 1963: 11.) 
"(Barthes, Roland. O grão da voz. Ob. cit.: 361,362 , res pectivamente.)
(Barthes, Roland. Le plaisit du texte. Ob. cit.: 85 .) do, vazio e preenchimento. Essas passagens me parecem extremamente importantes na medida em que, falando a respeito da tática do signo raciniana, Barthes esclarece muito sobre sua própria escrita: também nela se encontra uma economia que nunca perde de vista a relação tensa entre sentido posto/sentido retirado. Apesar de haver possíveis oscilações nessa economia de sua escrita ao longo dos anos (em seus últimos anos de vida, Barthes dizia ter "vontade de chegar a uma prática cada vez mais simples da língua”, e que achava que havia chegado, "talvez, o momento em que se deveria lutar menos, militar menos pelos textos, recuar um pouco [...] desconstruir menos os textos, jogar mais com a legibilidade"*), creio que, essencialmente, sua escrita sempre se manteve dentro de uma aventura do sentido, esticando ao máximo, sem rompê-lo, o elástico da legibilidade; pluralizando, sutilizando, complexificando, mas nunca abrindo mão do sentido. Algo entre o prazer e o gozo, entre o legível e o "escrevível”, entre a vanguarda e o clássico.

$\mathrm{O}$ "entre" é mesmo quase uma categoria em Barthes. O prazer do texto, por exemplo, é um livro que ronda todo o tempo essa noção: desde sua assunção, de saída, como um sujeito contraditório ("que abolisse, em si, as barreiras, as classes, as exclusões, não por sincretismo, mas por simples desembaraço desse velho espectro: a contradição lógica”*), passando pela "margem de indecisão" resguardada entre a conceituação dos textos de prazer e de gozo, até sua afirmação da dupla e contraditória perversidade ("perversidade”, em Barthes, é sempre sinônimo de felicidade: capacidade de extrair prazer independentemente de qualquer finalidade), de afirmar igualmente a experiência do prazer - ligada à cultura, à afirmação da identidade - e aquela do gozo, ligada à perda, à fenda, ao afastamento da cultura. A “fenda” [faille], que é também uma noção importante desse mesmo livro, uma outra figuração do "entre": a fenda é o lugar mesmo da erotização, do gozo: não se goza com a destruição, puramente, da cultura ou do sentido, mas com as transgressões sutis que se consegue criar entre essas bordas ${ }^{9}$. Daí a negação de Barthes à

\footnotetext{
9 "Entendo [...] por subversão sutil aquela que não se interessa diretamente à destruição, esquiva o paradigma e procura um outro termo: um terceiro termo, que não seja, entretanto, um termo de síntese, mas um termo excêntrico, inaudito" (Barthes, Roland. Le plaisir du texte. Ob. cit: 120).
} 
mera destruição do sentido, à vanguarda como violência (como "tédio", "violência" é um dos significantes que costuma estar presente quando Barthes se refere às vanguardas): negligenciando o lugar do entre, a violência perde o espaço da erotização; a violência está a um passo do estereótipo, da repetição, da doxa - de tudo aquilo que consiste. Barthes lembra que, etimologicamente, stereos, de onde vem estereótipo, quer dizer "sólido"*.

Daí a força crescente que foi tomando a categoria de "neutro" na escrita barthesiana. O neutro é esquivo ao paradigma da violência: não se opõe, é antes rizomático, produção de derivas. Se durante muito tempo Barthes encena a luta entre um valor negativo (o da "pseudo-Physis": a Lei, a referência, a analogia, o natural, a doxa etc.) e um valor positivo (o da "anti-Physis": a ficção, o romanesco, a desmistificação etc.), o advento do neutro permite que saia do paradigma da violência (a luta, o combate, o conflito, a arrogância...), afastando-se com isso de um comportamento típico de vanguarda ${ }^{10}$. O neutro é antes da ordem da sutileza, do deslocamento, da semiose. Há aí uma fina percepção histórica de Barthes, já situando sua própria escrita em concordância com um momento em que as vanguardas deixavam de fazer sentido. $\mathrm{E}$ deixavam de fazer sentido porque seu teatro perdia o sentido: como pensar as vanguardas sem a arrogância, o combate, a luta, e como pensar a pertinência disso tudo em uma época na França, provavelmente pós-1968, de desencantamento com o que se revelou serem utopias da função social da arte (decepção quanto a uma suposta transitividade da arte, capacidade de modificar diretamente o campo social), de assimilação da não-normatividade da arte, de reorganização do cenário político mundial? ${ }^{11} \mathrm{O}$ tom cool de Barthes já respon-

10 "Num primeiro tempo, tudo se reduz à luta de uma pseudo-Physis (Doxa, natural etc.) e de uma anti-Physis (todas as minhas utopias pessoais): uma é detestável, a outra é desejável. Entretanto num tempo ulterior, essa luta mesma lhe parece demasiadamente teatral; ela é então surdamente rejeitada, distanciada pela defesa (o desejo) do Neutro. O Neutro não é pois o terceiro termo - o grau zero - de uma oposição ao mesmo tempo semântica e conflituosa; é, num outro elo da cadeia infinita da linguagem, o segundo termo de um novo paradigma, cuja violência (o combate, a vitória, o teatro, a arrogância) é o termo pleno” (Barthes, Roland. Roland Barthes por Roland Barthes. Ob. cit: 149).

${ }^{11}$ Penso que o termo "vanguarda”, no contexto da arte moderna, não designa apenas uma prática do signo, mas toda a repercussão cultural provocada por essa prática. Assim, a radicalidade experimental não está proscrita pela história no 
dia, como ainda responde, a essa época, a nossa, como quer que a chamemos. Nem clássico, rigorosamente falando (pois o clássico pertence ao paradigma da representação), nem vanguarda (pois as vanguardas, repito, estão presas ao paradigma da violência).

Se é verdade, como acredito, que a pergunta fundamental de Barthes seja "que quer dizer isso?" (e não "por que isso?”, pergunta essa de inflexão científica ou religiosa), questão fundadora de uma ontologia, no caso barthesiano sempre provisória (pois se refere a formações históricas, não a essências de qualquer tipo), se é verdade, eu dizia, que a energia de Barthes é principalmente investida nessa aventura da significação, de dar sentido às coisas, de lhes dar espessura, de ampliar sua experiência, é também verdade que Barthes se inquieta com a própria aventura do sentido, mantendo como uma espécie de utopia a possibilidade de uma outra escrita. Dessa outra escrita, imaginada utopicamente no ensaio O rumor da língua, Barthes tenta se aproximar, seja teoricamente (através de sua própria descrição utópica), seja criticamente (como leitor do haicai japonês) ou em sua escrita (em passagens como as "anamneses" de Roland Barthes par Roland Barthes, ou os fragmentos marroquinos em Incidents). O que está em jogo aqui é um fantasma que nunca deixou de assombrá-lo: certas ressonâncias periféricas inevitáveis de uma aventura do sentido, por mais que ela se esmere em sutilezas e declarações de facticidade, isto é, os efeitos indesejados da assertividade (que roça uma arrogância da verdade) e a consistência semântica (que ameaça estancar o movimento dos significantes). Daí a utopia de uma "música do sentido"*, de um "rumor da língua”, de uma escrita que

tempo em que vivemos (nada impede que se continue a praticar uma tática extrema do signo, ostensivamente distante da cultura, ou mesmo hostil à cultura), mas sua ressonância social, essa sim, já não pode ser a mesma daquela do tempo das vanguardas: a experiência do choque (que está ligado ainda a um paradigma da normatividade) não existe mais, as utopias (sociais ou estéticas) também não são mais alimentadas etc. Portanto, a meu ver, as vanguardas já se tornaram um capítulo histórico, um "clássico da modernidade". Cabe aos artistas avaliar, como estou sugerindo que Barthes foi capaz de fazer com fina percepção, as implicações de suas táticas do signo em relação a esse momento histórico que é o nosso. 
fosse capaz de assimilar da música o puro significante, a nãosemantização, a não-representação; e do rumor, sua regularidade, sua continuidade, seu bom funcionamento maquínico. A utopia decorre precisamente do fato contraditório de se desejar algo que seja a um tempo música (puro significante) e sentido (inclusão do nível do significado). Como dispositivo contra as armadilhas do significado, Barthes elege o haicai e tenta - no lugar da espessura transparente de sua aventura semiológica incessantemente retomada pela pergunta "que quer dizer isso?" - o "fosco", a pura notação do real, sua superfície chapada (essa escrita se encontra nos já citados textos: "anamneses", de Roland Barthes par Roland Barthes, e os fragmentos marroquinos de Incidents $^{12}$ ). Mas o fosco não é uma solução, porque é incapaz de produzir movimento. A mera notação se revela uma sucessão de leituras estanques: freando-se a atribuição de sentidos, freia-se também o desencadeamento de novos significantes, e a leitura perde as derivas, a paixão pelos futuros com que certos significantes nos acenam. A meu ver, a escrita da notação funciona para Barthes como um lugar no caminho de seu ponto de fuga, de sua utopia de um rumor da língua. A prática do signo que melhor o define permanece sendo aquela de um equilíbrio tenso entre sentido posto e sentido retirado: uma aventura do sentido, da sutileza, da pluralidade, da espessura, da semiose, do legível esticado, do ritmo desimpedido; em suma, uma escrita, que, sem quebrar em nenhum momento o pacto da literatura - de desafiar o leitor, surpreendê-lo, frustrar suas expectativas, enriquecer seu repertório -, nunca deixa de quebrar seu próprio e tácito pacto: o de proporcionar uma experiência agradável de leitura.

12 "Chamo de anamnese a ação - mistura de gozo e de esforço - que leva o sujeito a reencontrar, sem o ampliar nem o fazer vibrar [o que seria a operação de espessura, detonada pela pergunta “o que é isso?”], uma tenuidade de lembrança: é o próprio haicai”. E, adiante: "Essas poucas anamneses são mais ou menos foscas (insignificantes; isentas de sentido)" (Barthes, Roland. Roland Barthes por Roland Barthes. Ob. cit: 126). 


\section{Francisco Bosco}

Poeta, letrista e ensaísta. Doutorando em Teoria Literária pela Universidade Federal do Rio de Janeiro. Publicou, entre outros, Da amizade (Rio de Janeiro: 7 Letras, 2003).

\section{Palavras-chave \\ Barthes \\ clássico \\ vanguarda \\ estratégias de escrita \\ modalidades de leitura \\ Key words \\ Barthes \\ classic \\ avant garde \\ writing strategies \\ reading modalities \\ Mots-clés \\ Barthes \\ classique \\ avant-gard \\ stratégies d'écriture \\ modalités de lecture}

Recebido em 30/09/2003

Aprovado em 05/12/2003

\section{Resumo}

O presente ensaio investiga as estratégias de escrita de Roland Barthes, suas relações com modalidades históricas da textualidade (como a modalidade "clássica" e aquela de vanguarda), e suas implicações relativamente ao ato da leitura. Nosso propósito é demonstrar que a escrita barthesiana está sempre se movendo no intervalo sutil entre o texto de vanguarda (que retarda a fluência da leitura, impondo sobre ela seu próprio e apropriado ritmo) e o texto "clássico" (que mantém um compromisso com uma prática confortável da leitura).

\section{Abstract}

This paper concerns Roland Barthes' strategies of writing, its relations to historical modalities of textuality (such as the "classical" and the avant garde ones), and its implications towards the act of reading. Our aim is to demonstrate that Barthes' writing always moves itself in the subtle interval between the avant garde text (which hinders the fluency of reading, imposing its own appropriate velocity) and the "classical" text (which is committed to a confortable practice of reading).

\section{Résumé}

Cet essai examine les stratégies d'écriture de Roland Barthes, ses rapports avec les modalités historiques de la textualité (comme la modalité classique et celle d'avantgarde) aussi bien que ses implications concernant l'acte de lecture. Notre propos est celui de démontrer que l'écriture barthesienne se déplace toujours dans cet intervalle subtil entre le texte d'avantgarde (qui retarde la fluidité de la lecture, lui imposant son rythme propre et approprié) et le texte "classique" (fidèle au pacte d'une pratique confortable de la lecture). 